\title{
SIMULATION STUDIES OF THE UNDERGROUND DC TRACTION SUBSTATION WITH AND WITHOUT ENERGY STORAGE DEVICE
}

This paper presents the results of the underground DC traction substation simulation studies for two versions: the substation equipped with the ESD (Energy Storage Device) and without the ESD. In these studies Supercapacitors Energy Storage System of energy capacity 10 $k W h$ and voltage $900 V$ is used. Simulation studies were performed in the Simscape/Simulink.

Keywords: Traction substation, underground, energy storage device, supercapacitor, simulation model, energy, power, Simscape/Simulink.

\section{Introduction}

Continuous increase in the cost of electricity requires the use of modern technology to reduce power consumption, including electricity storage devices known as (ESD - Energy Storage Device). Energy storage is used to compensate for the demand and supply of energy in stationary and mobile applications.

To the group of these devices accumulating energy we can include, among others ESD such as: Electrochemical Energy Storage Devices, Superconducting Magnetic Energy Storage Devices and Supercapacitors (also known as Ultracapacitors and Double Layer Supercapacitors) and Flywheels.

The possibility of a large number of charging and discharging cycles of supercapacitors $(10000 \div 500000)$ without degradation, distinguishing them clearly from the typical electrical energy storage, such as batteries. Double-layer capacitors combine, the advantages of traditional batteries and capacitors that is: the ability to quickly adapt to changes in loading and a high value of accumulated energy.

Ultracapacitors are used in: electric and rail vehicles, industrial applications, supplementing, or even replacing the batteries as a source of guaranteed supply voltage to the control, automation, etc.

The use of the ESD in underground traction substation could cause lower demand for electricity, which in turn is associated with its lower production, so as to limit carbon dioxide emissions into the environment. It is estimated that the production of $1 \mathrm{MWh}$ is associated with the emission of one ton of $\mathrm{CO}_{2}$ [1]. Another equally important aspect arising from the use of these devices is to stabilize the voltage in the traction line and the reduction of peak power consumption.

The analysis of the literature [2] shows that the greatest opportunity for practical application of traction substations described types of ESD has supercapacitors. Therefore, in simulation studies Supercapacitors Energy Storage System is included.

2. The underground substation simultation studies in two versions with and without energy storage devices

Simulation studies were carried out using Simscape package, which is an extension of simulation environment from Mathworks Simulink. Simscape is used for modeling and simulation of physical

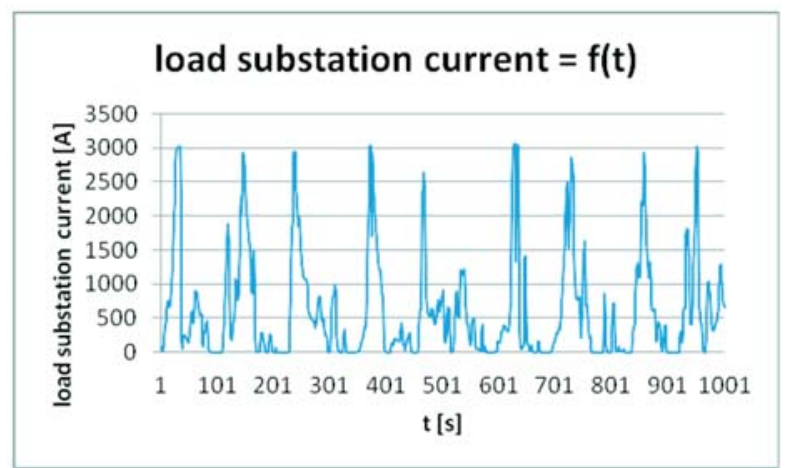

Fig. 1 The course of the instantaneous value of the load current substation (part of - the first 1000 values) beyond communication peak driving metro for the time period $12.00 .00-13.00 .00$

\footnotetext{
* Elzbieta Szychta ${ }^{1}$, Grzegorz Krawczyk ${ }^{1}$, Jozef Buday ${ }^{2}$, Jozef Kuchta² ${ }^{2}$ Jan Michalik $^{2}$

${ }^{1}$ Faculty of Transport and Electrical Engineering, Kazimierz Pulaski University of Technology and Humanities in Radom, Poland,

E-mail: e.szychta@uthrad.pl

${ }^{2}$ EVPU, Electrotechnical research and projecting company Nova Dubnica, Slovakia
} 
systems, such as: mechanical, electrical and hydraulics systems. Continuous process simulation studies are performed with a variable time step of the simulation.

Substation model input data are real DC substation load current obtained during the measurement on one of the Warsaw underground traction substation at a frequency of every 4-5 minutes (beyond communication peak driving metro trains - Fig. 1).

\subsection{The underground substation simulation studies without energy storage device}

The traction substation simulation model (Fig. 2) consists of a DC Substation subsystem block in series with the Load block.

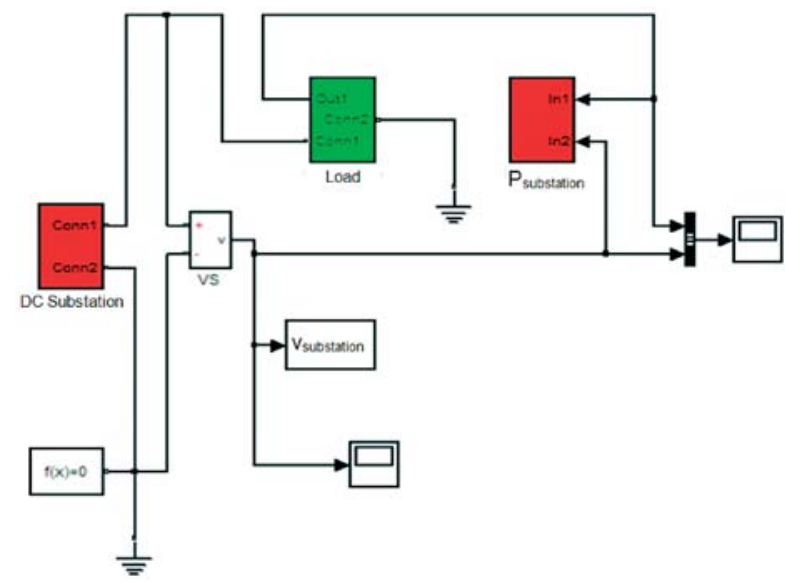

Fig. 2 The underground substation simulation model implemented in the Simscape

DC substation subsystem was modeled as a series connection of a voltage source, reflecting the substation load voltage $U_{0}=$ $=900 \mathrm{~V}$, resistor with a resistance $R_{\text {internal }}=0.0234 \Omega$ corresponding to the internal resistance of the substation [2]. However, substations load was modeled as a receiver controlled substation load current (Fig. 1) obtained on the basis of measurements carried out on the real underground traction substation (subsystem Load - Fig. 2). Instantaneous power substation waveform values are determined in $P_{\text {substation }}$ block (Fig. 2). Figs. 3 and 4 show the waveforms obtained from the simulation tests beyond communication peak driving metro.

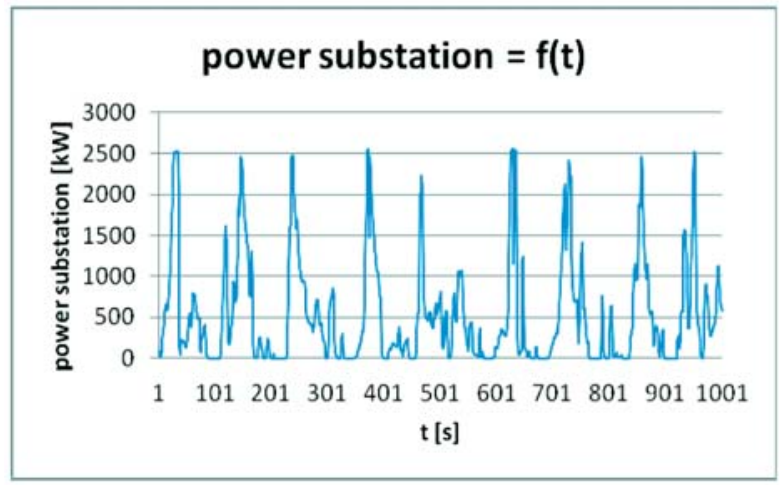

Fig. 4 Fragment course of instantaneous peak power substation beyond communication peak driving metro trains

\subsection{Simulation studies metro traction substations equipped with energy storage system (supercapacitors energy storage system)}

Supercapacitors are described by the same laws of physics as traditional capacitors, but the first one have a larger surface area to allow the storage of a larger charge and less space between the electrodes than conventional capacitors. The result is an increase of capacity and energy that can be stored in double-layer capacitors. Depending on the research approach double-layer capacitors are variously modeled. The variety of theoretical models describing supercapacitors, due to the fact that they are used in different areas, and that each model provides different accuracy of the processes described in these devices. Based on the analysis of the available literature of theoretical models describing the superca-
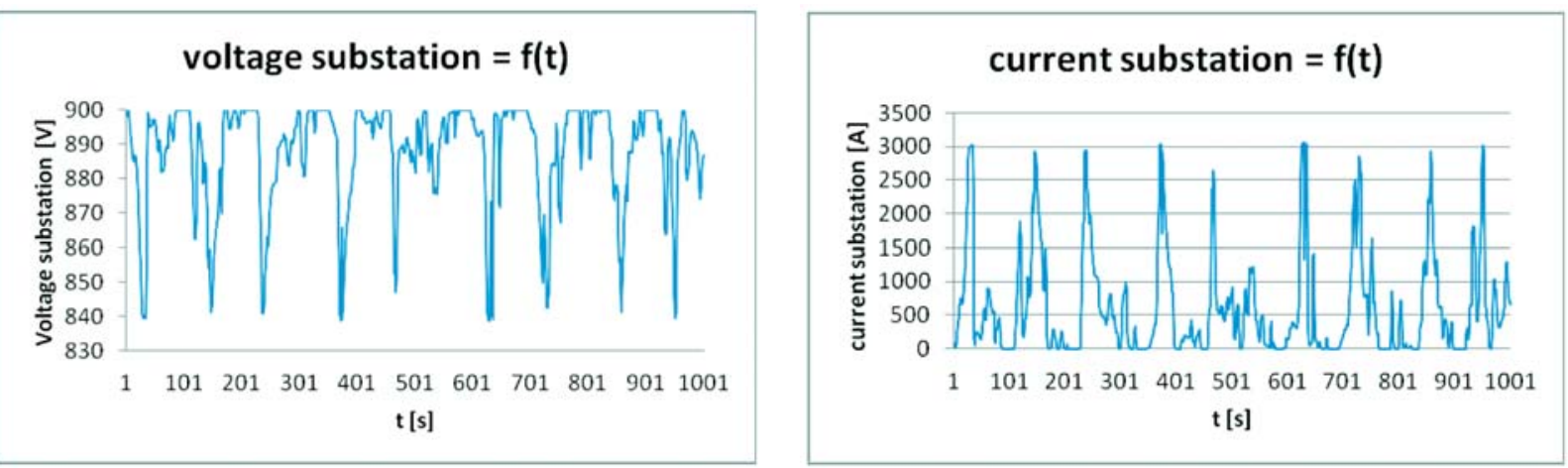

Fig. 3 The fragment of a course of the instantaneous values of voltage and current substation beyond communication peak driving metro trains 
pacitors [2, 3, 4], a model of supercapacitor (Fig. 5a) has been selected to the simulation studies.

The simulation studies take into account the following substitute parameters ESD (Fig. $5 b$ ): $C=93 \mathrm{~F}, E=10 \mathrm{kWh}, U=900 \mathrm{~V}$, $R_{s}=124.22 \Omega$ (resistance responsible for losses in supercapacitor), $R_{p}=6.440 \mathrm{k} \Omega$ (resistance reflecting supercapacitor self-discharge) $[2,5]$.

It was created with the appropriate combination of series-parallel single-supercapacitors. For the calculation of substitute parameters ESD LS Mtron supercapacitor rated voltage of $2.8 \mathrm{~V}$ and a rated capacity of $3000 \mathrm{~F}$ were adopted.

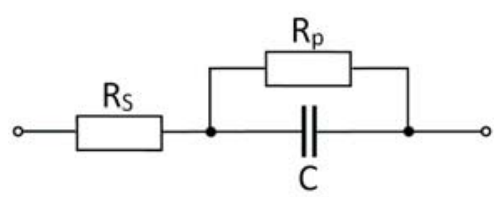

a) classical physical model capacitor without considering inductance terminals
$R_{s}$

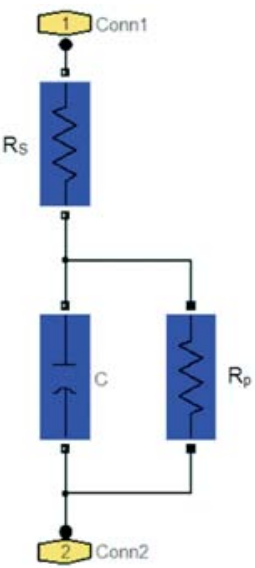

b) computer model of supercapacitor
Fig. 5 A model of Supercapacitors Energy Storage System: a) and b)

Underground substation simulation model equipped with the energy accumulation system (Fig. 6) were tested assuming an initial voltage ESD (initial conditions) of $900 \mathrm{~V}$. In this case, the voltage on the ESD in moment before commutation was equal to the value of the resultant voltage, which has been dimensioned Supercapacitors Energy Storage System.

Sequences on and off switches in the System charge and discharge ESD ("charging" and "dischaging") are performed by the control algorithm (Fig. 7) located in block S-function called Control (Fig. 6).

Symbols used in Fig. 7:

$v_{E S D}$ - instantaneous value of the voltage at the terminals of the power ESD;

$V_{M A X E S D}$ - nominal voltage ESD;

$V_{M I N \_E S D}-$ minimal (acceptable) voltage ESD (equation 1);

$$
V_{M I N_{-} E S D}=\frac{V_{M A X_{-} E S D}}{2}
$$

$v_{\text {sub }}$ - instantaneous value of the voltage at the terminals of the substation;

$V_{s}$ - switching voltage which is defined by the average voltage substations, above which the ESD is charging and discharging below this value;

$V_{a}$ - voltage, which is to be charged ESD. Based on the equation 2 the user can define the value range from $900 \mathrm{~V}$ to $500 \mathrm{~V}$.

$$
V_{a}=\frac{\left(V_{M A X_{-} E S D}-V_{M I N_{-} E S D}\right)}{g}
$$

where:

$g$ - a numerical value containing in the range of $0.5 \div 0.9$.

Operating regimes of substation control system with ESD are shown in Table 1.

Figures 8 - 11 contain waveforms obtained during the simulation studies with ESD.

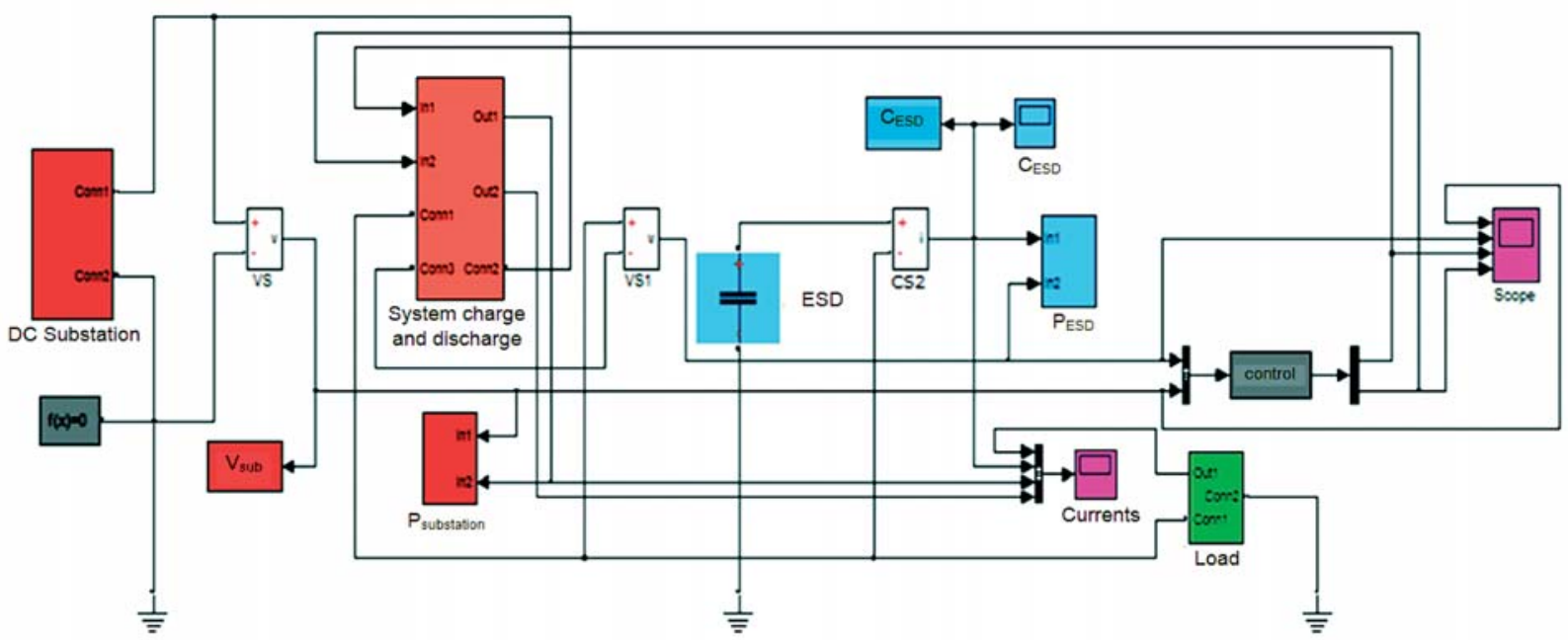

Fig. 6 A simulation of underground substation with ESD model 


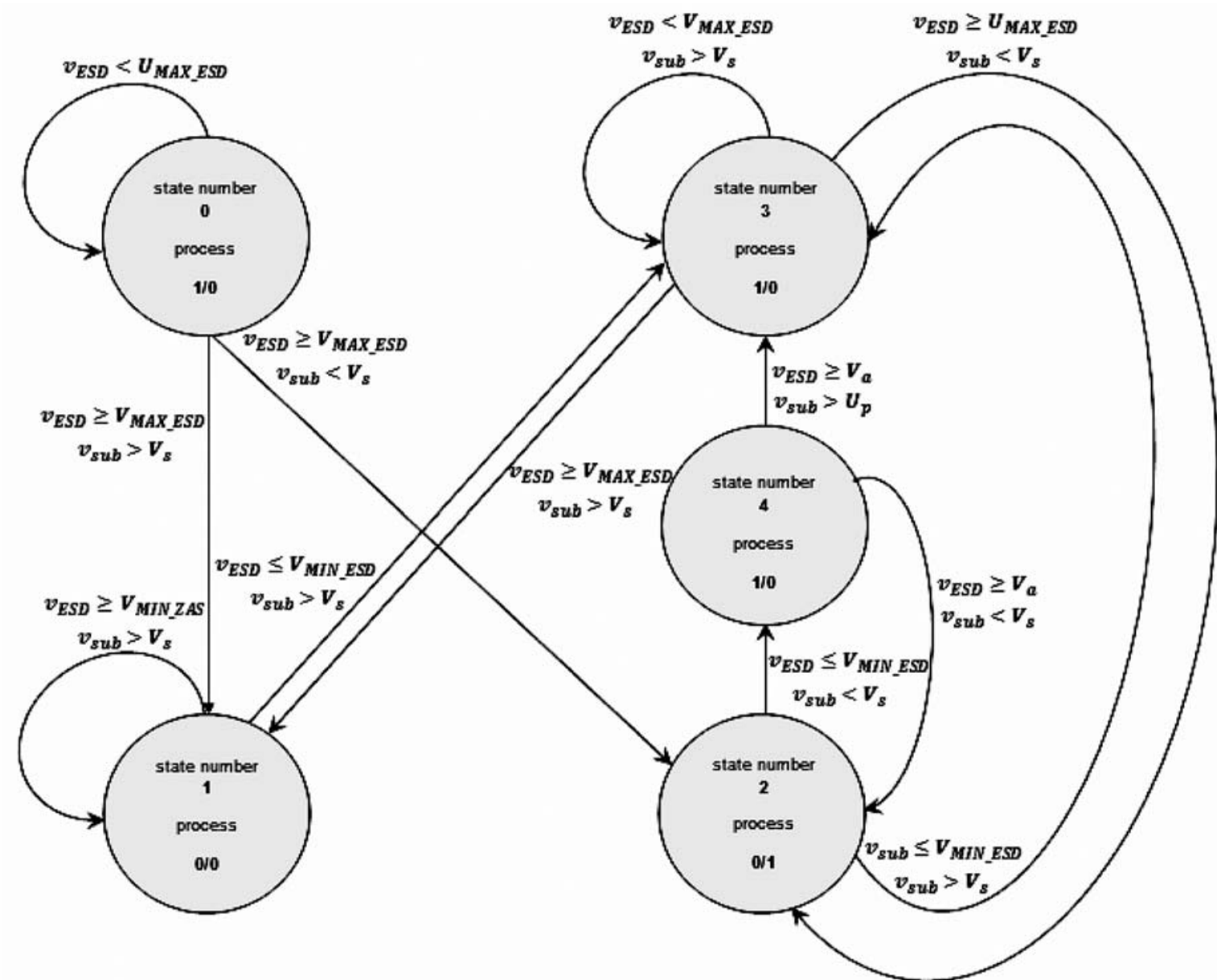

Fig. 7 A simulation model of the substation control system ESD

\begin{tabular}{|l|l|l|}
\hline \multicolumn{3}{|c|}{ Operating regimes of substation control system with ESD } \\
\hline \multicolumn{1}{|c|}{$1 / 0$} & \multicolumn{1}{|c|}{$0 / 1$} & \multicolumn{1}{c|}{$0 / 0$} \\
\hline $\begin{array}{l}\text { Value "1" on the left side shows the charging } \\
\text { state, and the value "0" to the right the } \\
\text { discharge state. }\end{array}$ & $\begin{array}{l}\text { Value "0" to the left side means no charging } \\
\text { status, and the number "1" to the right side } \\
\text { means the state of discharge. }\end{array}$ & $\begin{array}{l}\text { This means the system idle state that there is } \\
\text { neither charging nor discharging state. }\end{array}$ \\
\hline
\end{tabular}
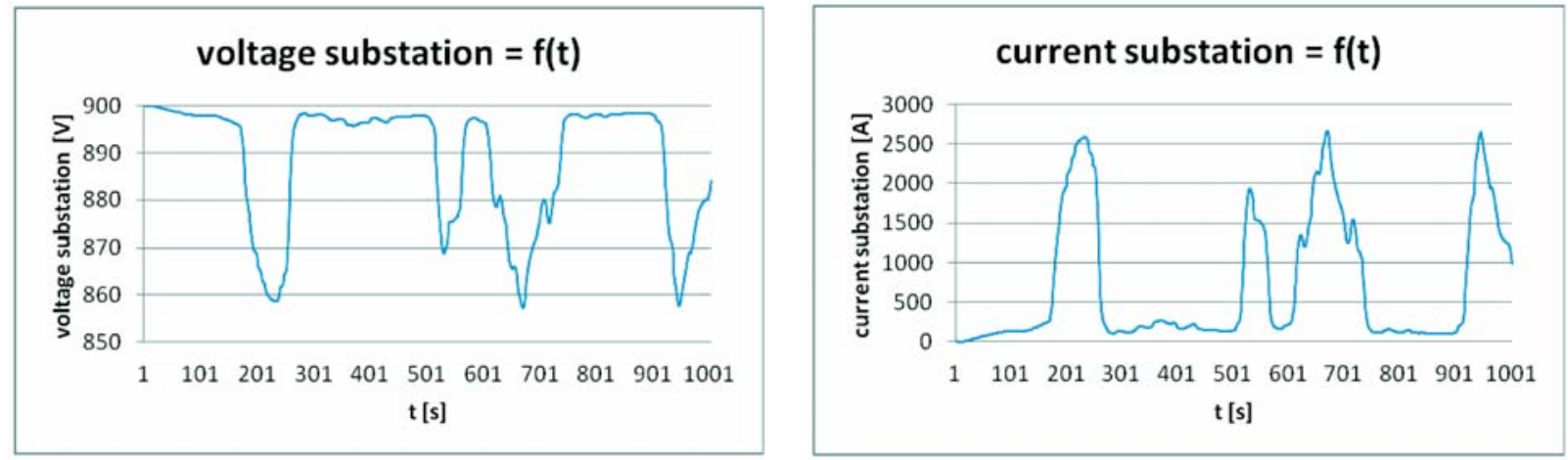

Fig. 8 The fragment of a course of the instantaneous values of voltage and current substation beyond communication peak driving metro trains 


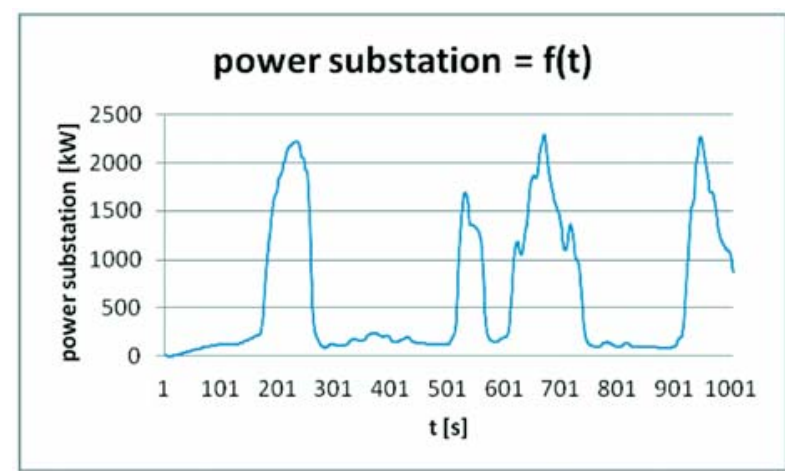

Fig. 9 The fragment of a course of the instantaneous values of power substation beyond communication peak driving metro trains

\section{The results of calculations of statistical parameters characterizing the voltage and power substation}

In the next part of this article the results of calculations of statistical parameters (arithmetic mean values and standard deviations) obtained during the simulation for variants: with and without Supercapacitors Energy Storage System were summarized.

Graphs presented in Fig. 12 show the results of calculations of the parameters characterizing the voltage traction substation for the course of the instantaneous values of load current substation beyond communication peak driving metro trains.

The average value of the same voltage substation beyond communication peak driving metro trains is lower by $0.06 \%$ as com-

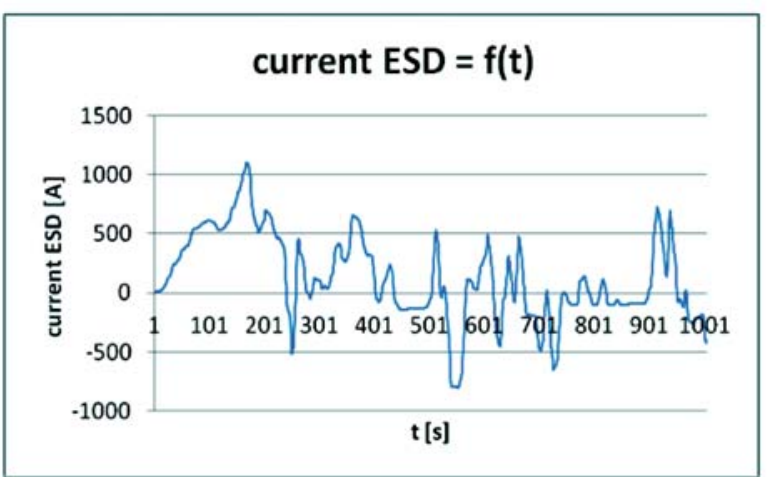

Fig. 10 The fragment of a course of the instantaneous values of voltage and current ESD in communication beyond peak driving metro trains

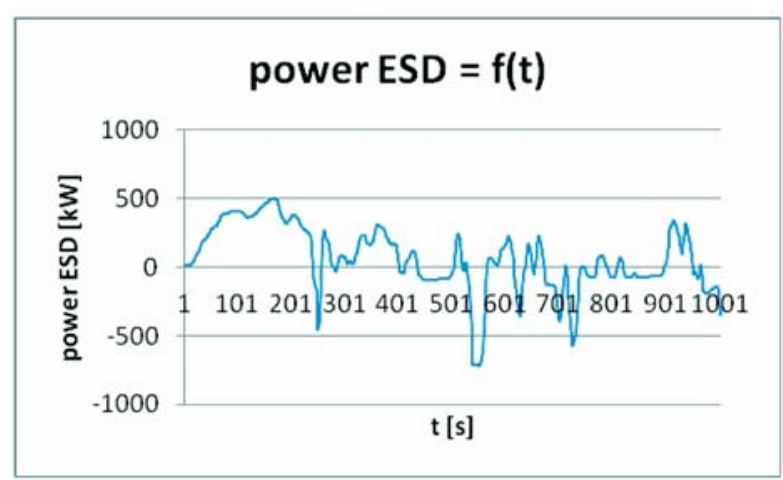

Fig. 11 The fragment of a course of the instantaneous values of power ESD in communication beyond peak driving metro trains

Based on the above waveforms (Figs. 3 - 4 and Figs. 8 - 11) it can be concluded that the application of ESD with appropriate parameters $(93 \mathrm{~F}, 10 \mathrm{kWh}$ and $900 \mathrm{~V})$ resulted in smoothing of voltage at the terminals of the substation as well as reducing the value of the current drawn from the substation, in relation to the same substation model version. pared to a substation of an electrical energy storage device. The standard deviation is by $23.22 \%$ higher than beyond communication peak driving metro trains. The graph contains the values of average power substation, beyond communication peak driving metro trains obtained for variants: with and without ESD is shown in Fig. 13.

Comparing the values of power substations in the system without and with ESD (energy capacity of $10 \mathrm{kWh}$ ) beyond peak driving metro trains, reduction of the power consumption of: $13.63 \%$ for the version of the substation not equipped with a system of accumulation was received.

\section{Conclusions}

Analysis of simulation results leads to the conclusion that the use of the substation equipped with energy storage device reduces the power consumed by the substation, in relation to the substation not fitted with ESD. In addition, electrical energy storage is beneficial for stabilizing the voltage substations. The more stable voltage, the more predictable movement of trains of the metro line, the better conditions for both accelerating trains, as well as the return of recuperative braking energy [6, 7]. In this case, it is possible to discharge ESD in the moment of the increased 

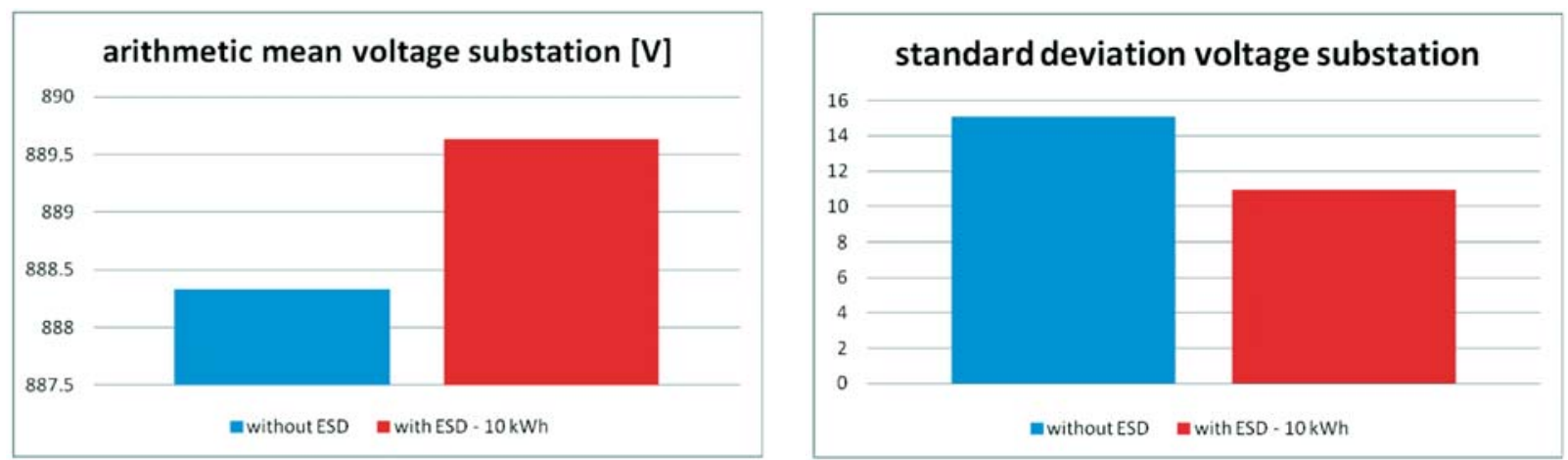

Fig. 12 The average values of voltage at the terminals of the substation and the standard deviation of the voltage without and with ESD $(E=10 \mathrm{kWh})$ beyond communication peak driving metro trains

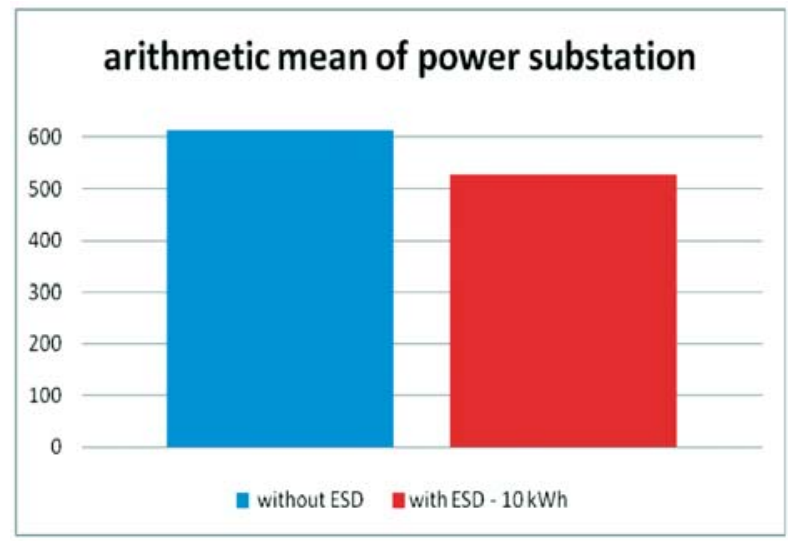

Fig. 13 The average values of power substation without and with ESD $(E=10 \mathrm{kWh})$ beyond communication peak driving metro trains

demand for power and accumulate in the ESD overcapacity present in the traction network.
ESD is more efficiently used in beyond communication peak driving metro trains than in the communication peak. This is due to the fact that in beyond communication peak distances between trains are larger, and so there are more variations of currents and voltages, therefore ESD will be used more efficiently than in the peak hours. The intensity of the train is greater at the peak of the metro trains running and therefore, it is more likely to exchange energy between adjacent trains. Substation load is more steady than in beyond communication peak driving metro trains.

The use of ESD reduces the phenomenon of surge voltage causing damage to the power system components. At the time when the vehicle goes into regenerative braking mode, and the power section is not a train that would be able to pick up the energy from braking, the voltage in the traction network rises to the level defined as the maximum allowable.

In addition, ESD can also be used as an additional source of energy supply in emergency situations, so that for example, it can result in a metro train to the nearest station, which is important from the point of view of safety of passengers.

\section{References}

[1] SZELAG, A.: Increasing the Energy Efficiency of Railway Transport. Rail Transport Technology, No. 12, 2008, ISSN $1232-3829$.

[2] KRAWCZYK, G.: Assessment of Effectiveness of the Application of Energy Storage Devices in the Underground Supply System. The doctoral dissertation. Technical University of Radom, 2012.

[3] GUERrero, M., ROMERO, E., BARRERO, F., MilAnES, M., GONZALEZ, E.: Overview of Medium Scale Energy Storage Systems. Prof. of conference IEEE $6^{\text {th }}$ Intern. Conference-Workshop Compatibility in Power Electronics, CPE2009, Badajoz, 2009, ISBN 978-1-4244-2856-4.

[4] SHI, L., CROW, M.: Comparison of Ultracapacitor Electric Circuit Models, IEEE Power and Energy Society General Meeting. Conversion and Delivery of Electrical Energy in the $21^{\text {st }}$ Century, pp. 1-6, July, 2008, ISSN 1932-5517.

[5] PAWEŁCZYK, M., KRAWCZYK, G.: A Method of the Determination of the Energy Storage Device Basic Parameters in the DC Electric Traction. Logistics, No. 3, 2007, ISSN 1231-5478.

[6] DOBRUCKY, B., OTCENASOVA, A., POKORNY, M., TABACEK, R.: The New Possibilities of Dynamic Compensation and Regeneration of Energy in Electric Traction. Communications - Scientific Letters of the University of Zilina, ISSN 1335-4205, Content $1 / 1999$.

[7] DOBRUCKY, B., ALTUS, J., SPANIK, P.: Synergic Influence of Power Electronics, Electric Traction and Electro-energetics. Communications - Scientific Letters of the University of Zilina, No. 2-3, 2001, ISSN 1335-4205. 